\title{
Eye Movement Desensitization and Reprocessing and Slow Wave Sleep: A Putative Mechanism of Action
}

\section{OPEN ACCESS}

Edited by:

Nuno Conceicao,

Universidade de Lisboa, Portugal

Reviewed by:

Arcady A. Putilov,

Institute of Molecular Biology and Biophysics (RAS), Russia

Guido Edoardo D'Aniello, Istituto Auxologico Italiano (IRCCS),

*Correspondence: Sara Carletto

sara.carletto@unito.it

Specialty section:

This article was submitted to Clinical and Health Psychology, a section of the journal Frontiers in Psychology

Received: 14 July 2017 Accepted: 19 October 2017 Published: 07 November 2017

Citation:

Pagani M, Amann BL, Landin-Romero $R$ and Carletto $S$ (2017) Eye Movement Desensitization and Reprocessing and Slow Wave

Sleep: A Putative Mechanism of Action. Front. Psychol. 8:1935. doi: 10.3389/fpsyg.2017.01935

\begin{abstract}
Marco Pagani', Benedikt L. Amann ${ }^{2,3,4}$, Ramon Landin-Romero ${ }^{5,6}$ and Sara Carletto ${ }^{7 *}$
${ }^{1}$ Institute of Cognitive Sciences and Technologies (CNR), Rome, Italy, ${ }^{2}$ Institut de Neuropsiquiatria i Addiccions, Centre Fòrum Research Unit, Parc de Salut Mar, Barcelona, Spain, ${ }^{3}$ Department of Psychiatry, Hospital del Mar Medical Research Institute, Autonomous University of Barcelona, Barcelona, Spain, ${ }^{4}$ Centro de Investigación Biomedica en Red de Salud Mental, Barcelona, Spain, ${ }^{5}$ Brain and Mind Centre and School of Psychology, The University of Sydney, Sydney, NSW, Australia, ${ }^{6}$ ARC Centre of Excellence in Cognition and its Disorders, Sydney, NSW, Australia, ${ }^{7}$ Department of Clinical and Biological Sciences, University of Turin, Turin, Italy
\end{abstract}

Eye Movement Desensitization and Reprocessing (EMDR) is considered highly efficacious for the treatment of Post-traumatic Stress Disorder and has proved to be a valid treatment approach with a wide range of applications. However, EMDR's mechanisms of action is not yet fully understood. This is an active area of clinical and neurophysiological research, and several different hypotheses have been proposed. This paper discusses a conjecture which focuses on the similarity between the delta waves recorded by electroencephalography during Slow Wave Sleep (SWS) and those registered upon typical EMDR bilateral stimulation (eye movements or alternate tapping) during recurrent distressing memories of an emotionally traumatic event. SWS appears to have a key role in memory consolidation and in the reorganization of distant functional networks, as well as Eye Movements seem to reduce traumatic episodic memory and favor the reconsolidation of new associated information. The SWS hypothesis may put forward an explanation of how EMDR works, and is discussed also in light of other theories and neurobiological findings.

Keywords: EMDR, mechanism of action, eye movements, sleep, slow wave sleep, REM, orienting response, working memory

\section{INTRODUCTION}

Eye Movement Desensitization and Reprocessing (EMDR) is a well-established psychological treatment for Post-traumatic Stress Disorder (PTSD) (Bradley et al., 2005; Chen et al., 2014). Furthermore, it has shown its efficacy in reducing anxiety levels in PTSD patients (Högberg et al., 2007, 2008; Bisson et al., 2013; Capezzani et al., 2013; McGuire et al., 2014; Faretta et al., 2016) and trauma-associated and psychiatric symptoms in various comorbid psychiatric diseases (Novo et al., 2014; Hase et al., 2015; Van Den Berg et al., 2015).

The neurobiological correlates of PTSD have been increasingly investigated by neuroimaging studies showing changes in cerebral blood flow (Bonne et al., 2003; Pagani et al., 2005; Lindauer et al., 2008; Nardo et al., 2011, 2015; for review see Bremner, 2007), metabolism (Pissiota et al., 2002; Osuch et al., 2008; Kim et al., 2012; Zhu et al., 2016), neuronal volume and density (Lindauer et al., 2004; Looi et al., 2009; Nardo et al., 2010, 2013; O'Doherty et al., 2015, 2017) and more recently in brain electric signal (Lee et al., 2014; Lobo et al., 2015), concordant with an involvement of the limbic system in the hyperarousal responsible for clinical symptoms. When reliving the traumatic events, the reduced control 
of the prefrontal cortex over hyperreactive amygdala and hippocampus is thought to be the core functional mechanisms of PTSD (Shin et al., 2006; Etkin and Wager, 2007).

Several neuroimaging investigations have demonstrated the effect of EMDR on cortical and sub-cortical regions involved in PTSD, depicting a clear association between disappearance of symptoms and the normalization of brain changes (Lansing et al., 2005; Pagani et al., 2007, 2012, 2015; Nardo et al., 2010; LandinRomero et al., 2013; Trentini et al., 2015; Laugharne et al., 2016; for review see Pagani et al., 2013). Whole session monitoring of cortical activations by EEG made EMDR the first psychotherapy in which neurobiological correlates have been depicted in real time (Pagani et al., 2011, 2012).

A strong demand for the need of knowing how EMDR works has followed and here we shortly describe some of the hypotheses.

The original theory of Adaptive Information Processing (AIP) proposed by Shapiro (2001) stated that humans have an innate information processing system that stores new experiences into existing memory networks in an adaptive state. Pathology arises when new information is inadequately processed and then stored in a maladaptive mode. When memories are adequately processed, symptoms can be eliminated and memories integrated.

The orienting and relaxation response (OR) hypothesis offers a theoretical framework which may support the explanation that bilateral stimulation produces relaxation. The $\mathrm{OR}$ is a natural attentional reflex that can occur with any novel environmental stimulus increasing readiness to respond to danger (Wilson et al., 1996; Barrowcliff et al., 2003, 2004). The initial freeze response is accompanied by changes in autonomic responses. In the absence of danger, it is rapidly replaced with a feeling of relaxation holding the potential to desensitize the traumatic memory, suppressing its associated disturbance. Eye movements (EMs) trigger an OR that can (i) facilitate access to the traumatic memory without avoidance and (ii) cause subsequent rapid extinction after the determination of no immediate threat (Armstrong and Vaughan, 1996).

The working memory account postulates that a central executive system is responsible for the integration of information stored in different slave subsystems, i.e., the visuospatial sketchpad processing visual and spatial information (Baddeley and Hitch, 1974; Hornsveld et al., 2010, 2011; van den Hout et al., 2010, 2011, 2012, 2013). The dual task (i.e., the EMs and the visual imagery) draws on the limited-capacity of the slave subsystems and on the central executive working memory resources. EMs, competing with and disrupting working memory resources, change the somatic perceptions, reduce vividness and decrease the emotionality of traumatic imagery.

The thalamic binding model (Bergmann, 2008) posits that bilateral stimulation facilitates the activation of the ventrolateral and central lateral thalamic nuclei via lateral cerebellum, facilitating the integration of somatosensory, memory, cognitive, emotional, and synchronized hemispheric functions that are disrupted in PTSD.

These studies assigned an important role to EMs, which seem to be not only the underpinning mechanism of EMDR complementing traumatic memory extinction, but also the factor accounting for a faster response to treatment compared to other psychotherapies (Nijdam et al., 2012).

It was recently highlighted (Pagani et al., 2012) that during successful EMDR therapy the cortical firing shifted from limbic structures toward regions with cognitive valence. In these studies, the occurrence of bilateral EMs was immediately accompanied by a synchronization of all cortical activity at a frequency in the delta range (Figure 1).

Despite these evidence, the role of EMs or, in general, bilateral stimulation in producing the neurobiological effects of EMDR is still unclear.

Based on this neurobiological evidence it is tempting to hypothesize a role of rapid eye movement (REM) and slow wave sleep (SWS) in the mechanism of action of EMDR. This follows the REM hypothesis for the mechanism of action of EMDR proposed by Stickgold (2002), according to which alternate bilateral stimulations typical of EMDR shift the brain into a memory processing mode similar to that of REM sleep.

Sleep has a bracing function, facilitates emotional processes and it is important for synaptic plasticity, emotional processing and memory formation. Long-lasting sleep disturbances are hallmark symptoms of PTSD that could interfere with a correct memory processing (Roszell et al., 1991; Leskin et al., 2002; Harvey et al., 2003) also causing functional and structural changes (Nardo et al., 2015).

\section{PHYSIOLOGICAL BASIS OF SWS AND MEMORY CONSOLIDATION}

To properly introduce our reasoning of a further role of SWS, it is essential to quote concepts and physiological bases well detailed in the works by Born et al. (2006) and Harper et al. (2009).

Memory recordings occurring during the waking state are temporarily stored in short-term memory and transferred to the neocortex during sleep. The combined episodic and emotional memory is replayed in the memory-editing matrix of the hippocampal-amygdalar complex as well as in neocortex during the first stage of SWS. In this process, memory is reinforced and extinguished by potentiation and depotentiation, respectively, of synapses of neurons recruited to form the memory chain. The excitatory glutamatergic pre-synaptic neurons release an amount of glutamate proportional to the strength of the signal. This in turn binds to the transmembrane $\alpha$-amino-3-hydroxy5-methyl-4-isoxazolepropionic acid glutamate receptor (AMPA), mediating the fast-synaptic transmission in central nervous system (CNS) networks, as the memory trace system. The opening of AMPA allows positively charged sodium into the post-synaptic neuron causing its depolarization. Stronger and repeated signals, as occurs during memory formation, cause more AMPA receptors to be transferred onto the surface of the post-synaptic neuron resulting in a larger sodium influx and in the opening of N-Methyl-D-aspartate (NMDA) glutamate receptors. This in turn favors the influx of positively charged calcium further strengthening the signal transmission. Synapses of the memory track are then potentiated, generating new proteins and gene expression resulting in the growth of new 


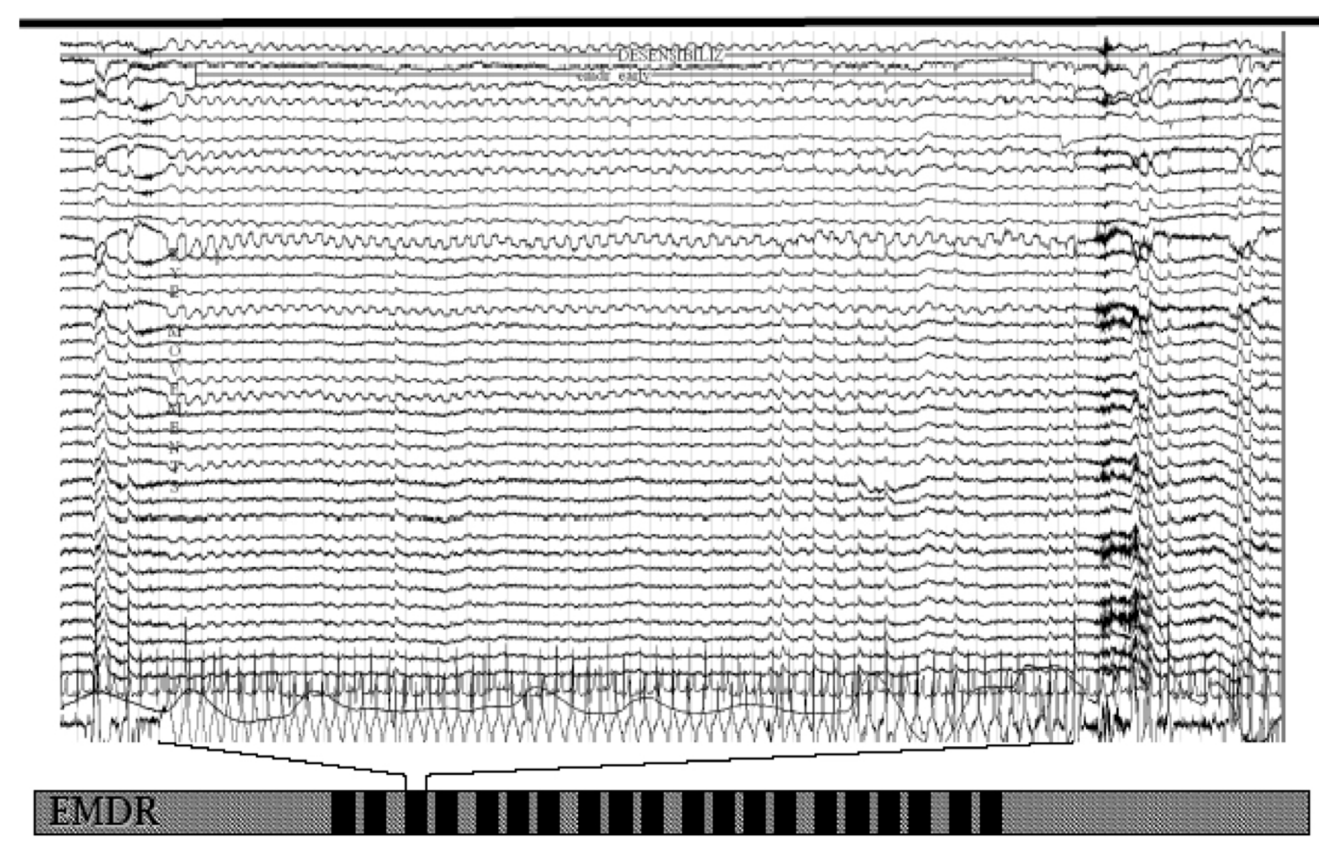

FIGURE 1 | EEG tracing upon eye movements during an eye movement desensitization and reprocessing (EMDR) session. Note the slow wave sleep (SWS)-like frequency from the beginning to the end of bilateral stimulation.

dendritic spines and new synaptic connections. The subsequent genetic expression and formation of permanent long-term memory occur mainly during REM sleep. In case of overpotentiation, low-frequency stimulation has a normalizing role depotentiating AMPA receptors, subsequently removed from the post-synaptic membrane, resulting in memory degradation. Following depotentiation, the receptors can no longer open and subsequently a substantial amount of them is removed from the post-synaptic membrane. The over-potentiated synapse is no longer able to convey the strong signals and henceforward is weakened. Potentiation and depotentiation (synaptic plasticity, adding or subtracting AMPA receptors) are carried out on synapses in the hippocampal-amygdalar complex and changes in their balance within the neural mechanisms of memory should be the molecular target for effective therapy.

Physiological normal sleep presents cyclic alternated pattern of REM and non-REM (SWS). EEG recordings show synchronous delta wave activity $(0.5-4$ cycles/s, i.e., $0.5-4 \mathrm{~Hz})$ during SWS, and synchronous theta waves (4-8 Hertz) during REM sleep. SWS provides an optimal milieu for transferring edited memories from the hippocampus to the neocortex, as well as stimulating the integration of these into neocortical neuronal networks.

When new information is filtered by the sensorimotor cortex and simultaneously transferred to hippocampal networks, only the strong and repeated signals induce specific replication when the memory is replayed during SWS in the following night(s). During such phase, the cortical networks in which encoding originally took place produce slow oscillations $(<1 \mathrm{~Hz})$ that reactivate the hippocampal memory. This memory replay originates an input directed toward the same cortical synapses in synchronicity with high frequency activity originating in the thalamus. The combined action of these two signals, as described above, potentiates the synapses supporting the consolidation of long-term memory. In this phase, it is the combination and the alternation of slow and rapid waves that favors the transfer from hippocampus back to neocortex of the fresh memory encoded during the waking state. During REM sleep, also due to the absence of slow waves, there is a decrease of such activity suggesting a more intense memory consolidation at neocortical level. In this phase, new associations of emotional events mediated by limbic structures take place.

To summarize, during wakefulness autobiographical, emotional and potentially traumatic events are conveyed and represented into the sensorimotor cortex. From such perceptual representation system information are transferred to subcortical limbic structures as hippocampus (episodic) and amygdala (associated affect) where an initial formation and potentiation of memory occurs. During SWS global synaptic weakening along with slow consolidation of information take place. Relevant memory circuits are reactivated and long-term potentiation is induced. During REM sleep, a further potentiation of the reactivated connections in neocortical memory network occurs.

The recording of the episodic aspect of memory in the hippocampus results in a normal potentiation of hippocampal synapses. Traumatic events may cause over-potentiation of amygdalar synapses and all post-synaptic AMPA binding sites will be occupied by glutamate. In such circumstances, the transfer to neocortex mainly through anterior cingulate cortex cannot occur since memories need the same synchronized 
signal intensity at emotional and cognitive level for the correct processing. Fragmented non-processed episodic and traumatic memories are trapped in hippocampus or amygdala without the contextual integration needed to encode them in long-term memory in association neocortex and persist sometimes for life.

\section{THE LINK BETWEEN SWS AND BILATERAL STIMULATION IN EMDR}

Bilateral stimulation typical of EMDR causes immediate slowing of the depolarization rate of neurons from the dominant waking state frequency of around $7 \mathrm{~Hz}$ to about $1.5 \mathrm{~Hz}$ (Harper et al., 2009; Pagani et al., 2011, 2012). The change of neuronal firing to low-frequency waves is a change from conditions favorable for synaptic potentiation to ones favorable for depotentiation.

In animals, low-frequency stimulation ( 5 Hertz) has shown to cause a depotentiation of amygdalar AMPA receptors involved in the retention of traumatic memory (Mao, 2006) and 900 stimuli at $1-5 \mathrm{~Hz}$ depotentiated synapses mediating memory (Kopp et al., 2006). This is about the number and the frequency of EMs during a typical EMDR session in which holding the attention on a traumatic memory targets the relevant synapses where it was originally encoded. It is worth noting that SWS occurs 3-5 times during night while bilateral stimulation is performed 25-30 times upon each EMDR session. This might account for the very fast processing of bad memories experienced by clients in a single or in a few EMDR sessions.

During EMDR sessions therapists performs bilateral stimulation at about $1-2$ cycles/s $(1-2 \mathrm{~Hz})$ eliciting slow waves similar to the ones recorded during SWS. This suggests that memories aroused during therapy are continuously reactivated, replayed and encoded into existing memory networks.

A memory trace is weakened when held in attention and in such condition it is easily depotentiated. During an EMDR session the focus of the attention is on the fragmented traumatic memory and its synaptic traces in the amygdalarhippocampal complex. EMDR decreases affective aspects of traumatic memories in the amygdala and leaves intact the associated cognitive aspects in the hippocampus. The affective and cognitive aspects of the memory are then merged in anterior cingulate cortex and sent to higher brain centers, where an encoding process within the association areas provide a clear distinction between the past and the present. The pathological memory trace is no longer confined by its over-potentiation to the limbic memory areas.

According to this model, desensitization indicated by the $D$ in EMDR results from Depotentiation of fear memory synapses (Harper et al., 2009).

These speculations are supported by some recent neurophysiological findings. Harper et al. (2009) reported that, upon EMs, EEG tracing recorded in the delta range (1.5 Hertz) resembled the ones registered during SWS by Rétey et al. (2005). Such delta waves also paced $\beta$-waves (frequency of 13.5 Hertz), speaking in favor, during bilateral stimulation, of a general resonance in brain electric activity consonant with EMs.
Recently, Pagani et al. $(2011,2012)$ in two separate investigations reported that the eye-movement component of EMDR induced an EEG pattern similar to the one described by Harper et al. (2009). This seems to confirm that the neurophysiological effect of bilateral stimulation by means of EMs or smooth pursuit $(1-2 \mathrm{~Hz})$ produces delta waves activity as during SWS $(0.5-3 \mathrm{~Hz})$.

It can be further speculated that the consolidation of emotional memory in neocortex during an EMDR session, often resulting in a sudden symptoms disappearance, is associated with periods in which slow $(1.5 \mathrm{~Hz})$ and fast $(4-12 \mathrm{~Hz}$, thetaalpha, typical waking state) waves are elicited by the alternation of bilateral stimulation and installation of positive cognition. This would mimic the previously described condition occurring during sleep in which memories are transferred from subcortical structures and encoded into neocortex.

If confirmed by future studies, the molecular and neurobiological mechanisms underlying our model could merge the effects explained by the OR theory, by the working memory account and by the hypothesis of Stickgold (2008).

In fact, we posit that bilateral stimulation mimics the lowfrequency stimulation typical of SWS, inducing a depotentiation of the AMPA receptors of amygdalar synapses, which in turn lead to a weakening of the traumatic memory. This reduction of the over-potentiation of amygdalar synapses makes traumatic memory more accessible, and facilitates the connection between emotional memory and episodic memory, thus promoting a shift of memory to associative and neocortical areas. This is also consonant with the findings of Pagani et al. (2012) that showed in EMDR a shift of the traumatic memories from an implicit subcortical status to cortical regions that integrate them into existing semantic memory. Moreover, the depotentiation caused by low-frequency stimulation (i.e., EMDR bilateral stimulation) results in memory degradation and weakening, thus exerting the effect of reducing the vividness and emotionality of the traumatic memory, finally promoting a detachment from the past traumatic event.

These effects are the same described in clinical setting by the $\mathrm{OR}$ and the working memory models.

In assonance with OR hypothesis, delta waves elicited by bilateral stimulation facilitate the access to the dysfunctionally stored traumatic memory during wake consciousness. Thanks also to the absence of danger characterized by the therapeutic context, favoring relaxation, the extinction of traumatic memory and its reprocessing by associative and cortical areas could take place. The relaxation associated with the fading of the emotional memory is likely due to the reduction of the over-potentiation of amygdalar synapses occurring in real time during EMDR therapy.

Our speculation is also in agreement with the working memory account, since the effects of SWS-like neurophysiological conditions reproduced by EMDR bilateral stimulation, reducing in real time the over-potentiation of the amygdala and the relative hyperarousal, impact during therapy on vividness and on emotionality of traumatic memories, contributing to the sense of distancing from the original event described by patients. 
Both models are based on the weakening of a memory when recalled and held in attention, but with different underlying explanations. In the working memory account, the imagery deflation effect is explained by the dual tasking (i.e., the competition between recall of the memory and the bilateral stimulation task) that affect the limited-capacity of the working memory. In our SWS model, memory degradation is determined by the depotentiation of AMPA receptors by EMDR bilateral stimulations miming SWS low-frequency stimulations occurring during sleep.

Lastly, our hypothesis follows the footsteps drawn by Stickgold (2002, 2008), deepening the role of SWS-like state induced by EMDR bilateral stimulation which promotes the transfer of episodic memory to semantic memory, that will be then consolidated during REM-like states.

Hippocampal-amygdala complex memories are transferred to neocortex, replayed, and consolidated into semantic associative memory networks. Information is then integrated to create meaning and learning from the event. The transfer might occur during slow-wave-sleep (1-3 Hz) and definitive memory consolidation during REM sleep (about 4-6 Hz). The traumatic episodic memory is weakened and then removed from hippocampus.

\section{CONCLUSION}

In conclusion, this perspective article proposes that bilateral stimulation during EMDR might reproduce the

\section{REFERENCES}

Armstrong, M. S., and Vaughan, K. (1996). An orienting response model of eye movement desensitization. J. Behav. Ther. Exp. Psychiatry 27, 21-32. doi: 10.1016/0005-7916(95)00056-9

Baddeley, A. D., and Hitch, G. (1974). Working memory. Psychol. Learn. Motiv. 8, 47-89. doi: 10.1016/S0079-7421(08)60452-1

Barrowcliff, A. L., Gray, N. S., Freeman, T. C., and MacCulloch, M. J. (2004). Eye-movements reduce the vividness, emotional valence and electrodermal arousal associated with negative autobiographical memories. J. Forensic Psychiatry Psychol. 15, 325-345. doi: 10.1080/1478994041000167 3042

Barrowcliff, A. L., Gray, N. S., MacCulloch, S., Freeman, T. C. A., and MacCulloch, M. J. (2003). Horizontal rhythmical eye movements consistently diminish the arousal provoked by auditory stimuli. Br. J. Clin. Psychol. 42, 289-302. doi: 10.1348/01446650360703393

Bergmann, U. (2008). The neurobiology of EMDR: exploring the thalamus and neural integration. J. EMDR Pract. Res. 2, 300-314. doi: 10.1891/1933-3196.2.4. 300

Bisson, J. I., Roberts, N. P., Andrew, M., Cooper, R., and Lewis, C. (2013). Psychological therapies for chronic post-traumatic stress disorder (PTSD) in adults. Cochrane Database Syst. Rev. 12:CD003388. doi: 10.1002/14651858. CD003388.pub4

Bonne, O., Gilboa, A., Louzoun, Y., Brandes, D., Yona, I., Lester, H., et al. (2003). Resting regional cerebral perfusion in recent posttraumatic stress disorder. Biol. Psychiatry 54, 1077-1086. doi: 10.1016/S0006-3223(03) 00525-0

Born, J., Rasch, B., and Gais, S. (2006). Sleep to remember. Neuroscientist 12, 410-424. doi: 10.1177/1073858406292647

Bradley, R., Greene, J., Russ, E., Dutra, L., and Westen, D. (2005). A multidimensional meta-analysis of psychotherapy for PTSD. Am. J. Psychiatry 162, 214-227. doi: 10.1176/appi.ajp.162.2.214 neurophysiological conditions favorable for memory integration in associative neocortex, weakening the perception of the traumatic memory, reducing its vividness and inducing a sense of relaxation and safety.

Quoting Stickgold (2002): "We are not claiming that we have solid evidence for all of the links and interpretations in the train of logic presented here.[...] Our goal is to demonstrate that there is a reasonable explanation of how EMDR works, which is consonant with modern neurobiology and cognitive neuroscience[...]."

Our aim is also to encourage further research in investigating the mechanisms of action of already proven effective psychotherapies such as EMDR, with experimental studies that might combine theoretical assumptions, molecular biology, neurophysiology, neuropsychology, brain imaging and clinical evidences in patients' cohorts.

\section{AUTHOR CONTRIBUTIONS}

MP was responsible for the conception of the work, that was integrated and critically revised by SC, BA, and RL-R. All authors have approved the final manuscript.

\section{ACKNOWLEDGMENT}

We would like to thank EMDR Italy Association for continuous support and Dr. Katja Gasperini for her help in English editing.

Bremner, J. D. (2007). Neuroimaging in posttraumatic stress disorder and other stress-related disorders. Neuroimaging Clin. N. Am. 17, 523-538. doi: 10.1016/ j.nic.2007.07.003

Capezzani, L., Ostacoli, L., Cavallo, M., Carletto, S., Fernandez, I., Solomon, R., et al. (2013). EMDR and CBT for cancer patients: comparative study of effects on PTSD, anxiety, and depression. J. EMDR Pract. Res. 7, 134-143. doi: 10.1891/ 1933-3196.7.3.134

Chen, Y.-R., Hung, K.-W., Tsai, J.-C., Chu, H., Chung, M.-H., Chen, S.-R., et al. (2014). Efficacy of eye-movement desensitization and reprocessing for patients with posttraumatic-stress disorder: a meta-analysis of randomized controlled trials. PLOS ONE 9:e103676. doi: 10.1371/journal.pone.0103676

Etkin, A., and Wager, T. D. (2007). Functional neuroimaging of anxiety: a metaanalysis of emotional processing in PTSD, social anxiety disorder, and specific phobia. Am. J. Psychiatry 164, 1476-1488. doi: 10.1176/appi.ajp.2007.07030504

Faretta, E., Borsato, T., Civilotti, C., Fernandez, I., and Pagani, M. (2016). EMDR and CBT: a comparative clinical study with oncological patients. J. EMDR Pract. Res. 10, 215-227. doi: 10.1891/1933-3196.10.3.215

Harper, M. L., Rasolkhani-Kalhorn, T., and Drozd, J. F. (2009). On the neural basis of EMDR therapy: insights from qEEG studies. Traumatology 15, 81-95. doi: $10.1177 / 1534765609338498$

Harvey, A. G., Jones, C., and Schmidt, D. A. (2003). Sleep and posttraumatic stress disorder: a review. Clin. Psychol. Rev. 23, 377-407. doi: 10.1016/S0272-7358(03) 00032-1

Hase, M., Balmaceda, U. M., Hase, A., Lehnung, M., Tumani, V., Huchzermeier, C., et al. (2015). Eye movement desensitization and reprocessing (EMDR) therapy in the treatment of depression: a matched pairs study in an inpatient setting. Brain Behav. 5, 1-9. doi: 10.1002/brb3.342

Högberg, G., Pagani, M., Sundin, O., Soares, J., Åberg-Wistedt, A., Tärnell, B., et al. (2007). On treatment with eye movement desensitization and reprocessing of chronic post-traumatic stress disorder in public transportation workers A randomized controlled trial. Nord. J. Psychiatry 61, 54-61. doi: 10.1080/ 08039480601129408 
Högberg, G., Pagani, M., Sundin, O., Soares, J., Aberg-Wistedt, A., Tärnell, B., et al. (2008). Treatment of post-traumatic stress disorder with eye movement desensitization and reprocessing: outcome is stable in 35-month follow-up. Psychiatry Res. 159, 101-108. doi: 10.1016/j.psychres.2007.10.019

Hornsveld, H. K., Houtveen, J. H., Vroomen, M., Kapteijn, I., Aalbers, D., and van den Hout, M. A. (2011). Evaluating the effect of eye movements on positive memories such as those used in resource development and installation. J. EMDR Pract. Res. 5, 146-155. doi: 10.1891/1933-3196.5.4.146

Hornsveld, H. K., Landwehr, F., Stein, W., Stomp, M. P. H., Smeets, M. A. M., and van den Hout, M. A. (2010). Emotionality of loss-related memories is reduced after recall plus eye movements but not after recall plus music or recall only. J. EMDR Pract. Res. 4, 106-112. doi: 10.1891/1933-3196.4.3.106

Kim, S.-Y., Chung, Y.-K., Kim, B. S., Lee, S. J., Yoon, J.-K., and An, Y.-S. (2012). Resting cerebral glucose metabolism and perfusion patterns in women with posttraumatic stress disorder related to sexual assault. Psychiatry Res. Neuroimaging 201, 214-217. doi: 10.1016/j.pscychresns.2011.08.007

Kopp, C., Longordo, F., Nicholson, J. R., and Lüthi, A. (2006). Insufficient sleep reversibly alters bidirectional synaptic plasticity and NMDA receptor function. J. Neurosci. 26, 12456-12465. doi: 10.1523/JNEUROSCI.2702-06.2006

Landin-Romero, R., Novo, P., Vicens, V., McKenna, P. J., Santed, A., PomarolClotet, E., et al. (2013). EMDR therapy modulates the default mode network in a subsyndromal, traumatized bipolar patient. Neuropsychobiology 67, 181-184. doi: 10.1159/000346654

Lansing, K., Amen, D. G., Hanks, C., and Rudy, L. (2005). High-resolution brain SPECT imaging and eye movement desensitization and reprocessing in police officers with PTSD. J. Neuropsychiatry Clin. Neurosci. 17, 526-532. doi: 10.1176/ appi.neuropsych.17.4.526

Laugharne, J., Kullack, C., Lee, C. W., McGuire, T., Brockman, S., Drummond, P. D., et al. (2016). Amygdala volumetric change following psychotherapy for posttraumatic stress disorder. J. Neuropsychiatry Clin. Neurosci. 28, 312-318. doi: 10.1176/appi.neuropsych.16010006

Lee, S.-H., Yoon, S., Kim, J.-I., Jin, S.-H., and Chung, C. K. (2014). Functional connectivity of resting state EEG and symptom severity in patients with posttraumatic stress disorder. Prog. Neuropsychopharmacol. Biol. Psychiatry 51, 51-57. doi: 10.1016/j.pnpbp.2014.01.008

Leskin, G. A., Woodward, S. H., Young, H. E., and Sheikh, J. I. (2002). Effects of comorbid diagnoses on sleep disturbance in PTSD. J. Psychiatr. Res. 36, 449-452. doi: 10.1016/S0022-3956(02)00025-0

Lindauer, R. J. L., Booij, J., Habraken, J. B. A., van Meijel, E. P. M., Uylings, H. B. M., Olff, M., et al. (2008). Effects of psychotherapy on regional cerebral blood flow during trauma imagery in patients with post-traumatic stress disorder: a randomized clinical trial. Psychol. Med. 38, 543-554. doi: 10.1017/ S0033291707001432

Lindauer, R. J. L., Vlieger, E.-J., Jalink, M., Olff, M., Carlier, I. V. E., Majoie, C. B. L. M., et al. (2004). Smaller hippocampal volume in Dutch police officers with posttraumatic stress disorder. Biol. Psychiatry 56, 356-363. doi: 10.1016/j. biopsych.2004.05.021

Lobo, I., Portugal, L. C., Figueira, I., Volchan, E., David, I., Garcia Pereira, M., et al. (2015). EEG correlates of the severity of posttraumatic stress symptoms: a systematic review of the dimensional PTSD literature. J. Affect. Disord. 183, 210-220. doi: 10.1016/j.jad.2015.05.015

Looi, J. C. L., Maller, J. J., Pagani, M., Högberg, G., Lindberg, O., Liberg, B., et al. (2009). Caudate volumes in public transportation workers exposed to trauma in the Stockholm train system. Psychiatry Res. 171, 138-143. doi: 10.1016/j. pscychresns.2008.03.011

Mao, S.-C. (2006). Extinction training in conjunction with a partial agonist of the glycine site on the NMDA receptor erases memory trace. J. Neurosci. 26, 8892-8899. doi: 10.1523/JNEUROSCI.0365-06.2006

McGuire, T. M., Lee, C. W., and Drummond, P. D. (2014). Potential of eye movement desensitization and reprocessing therapy in the treatment of posttraumatic stress disorder. Psychol. Res. Behav. Manag. 7, 273-283. doi: 10.2147/ PRBM.S52268

Nardo, D., Högberg, G., Flumeri, F., Jacobsson, H., Larsson, S. A., Hällström, T., et al. (2011). Self-rating scales assessing subjective well-being and distress correlate with rCBF in PTSD-sensitive regions. Psychol. Med. 41, 2549-2561. doi: 10.1017/S0033291711000912

Nardo, D., Högberg, G., Jonsson, C., Jacobsson, H., Hällström, T., and Pagani, M. (2015). Neurobiology of sleep disturbances in PTSD patients and traumatized controls: MRI and SPECT Findings. Front. Psychiatry 6:134. doi: 10.3389/fpsyt. 2015.00134

Nardo, D., Högberg, G., Lanius, R. A., Jacobsson, H., Jonsson, C., Hällström, T., et al. (2013). Gray matter volume alterations related to trait dissociation in PTSD and traumatized controls. Acta Psychiatr. Scand. 128, 222-233. doi: 10.1111 /acps.12026

Nardo, D., Högberg, G., Looi, J. C. L., Larsson, S., Hällström, T., and Pagani, M. (2010). Gray matter density in limbic and paralimbic cortices is associated with trauma load and EMDR outcome in PTSD patients. J. Psychiatr. Res. 44, 477-485. doi: 10.1016/j.jpsychires.2009.10.014

Nijdam, M. J., Gersons, B. P. R., Reitsma, J. B., De Jongh, A., and Olff, M. (2012). Brief eclectic psychotherapy v. eye movement desensitisation and reprocessing therapy for post-traumatic stress disorder: randomised controlled trial. Br. J. Psychiatry 200, 224-231. doi: 10.1192/bjp.bp.111.099234

Novo, P., Landin-Romero, R., Radua, J., Vicens, V., Fernandez, I., Garcia, F., et al. (2014). Eye movement desensitization and reprocessing therapy in subsyndromal bipolar patients with a history of traumatic events: a randomized, controlled pilot-study. Psychiatry Res. 219, 122-128. doi: 10.1016/j.psychres. 2014.05.012

O’Doherty, D. C. M., Chitty, K. M., Saddiqui, S., Bennett, M. R., and Lagopoulos, J. (2015). A systematic review and meta-analysis of magnetic resonance imaging measurement of structural volumes in posttraumatic stress disorder. Psychiatry Res. 232, 1-33. doi: 10.1016/j.pscychresns.2015.01.002

O’Doherty, D. C. M., Tickell, A., Ryder, W., Chan, C., Hermens, D. F., Bennett, M. R., et al. (2017). Frontal and subcortical grey matter reductions in PTSD. Psychiatry Res. 266, 1-9. doi: 10.1016/j.pscychresns.2017.05.008

Osuch, E. A., Willis, M. W., Bluhm, R., Csts Neuroimaging Study Group, Ursano, R. J., and Drevets, W. C. (2008). Neurophysiological responses to traumatic reminders in the acute aftermath of serious motor vehicle collisions using [15O]-H2O positron emission tomography. Biol. Psychiatry 64, 327-335. doi: 10.1016/j.biopsych.2008.03.010

Pagani, M., Di Lorenzo, G., Monaco, L., Daverio, A., Giannoudas, I., La Porta, P., et al. (2015). Neurobiological response to EMDR therapy in clients with different psychological traumas. Front. Psychol. 6:1614. doi: 10.3389/fpsyg.2015. 01614

Pagani, M., Di Lorenzo, G., Monaco, L., Niolu, C., Siracusano, A., Verardo, A. R., et al. (2011). Pretreatment, intratreatment, and posttreatment EEG imaging of EMDR: methodology and preliminary results from a single case. J. EMDR Pract. Res. 5, 42-56. doi: 10.1891/1933-3196.5.2.42

Pagani, M., Di Lorenzo, G., Verardo, A. R., Nicolais, G., Monaco, L., Lauretti, G., et al. (2012). Neurobiological correlates of EMDR monitoring - An EEG study. PLOS ONE 7:e45753. doi: 10.1371/journal.pone.0045753

Pagani, M., Högberg, G., Fernandez, I., and Siracusano, A. (2013). Correlates of EMDR therapy in functional and structural neuroimaging: a critical summary of recent findings. J. EMDR Pract. Res. 7, 29-38. doi: 10.1891/1933-3196. 7.1.29

Pagani, M., Högberg, G., Salmaso, D., Nardo, D., Sundin, Ö, Jonsson, C., et al. (2007). Effects of EMDR psychotherapy on 99mTc-HMPAO distribution in occupation-related post-traumatic stress disorder. Nucl. Med. Commun. 28, 757-765. doi: 10.1097/MNM.0b013e3282742035

Pagani, M., Högberg, G., Salmaso, D., Tärnell, B., Sanchez-Crespo, A., Soares, J., et al. (2005). Regional cerebral blood flow during auditory recall in 47 subjects exposed to assaultive and non-assaultive trauma and developing or not posttraumatic stress disorder. Eur. Arch. Psychiatry Clin. Neurosci. 255, 359-365. doi: 10.1007/s00406-005-0559-9

Pissiota, A., Frans, O., Fernandez, M., von Knorring, L., Fischer, H., and Fredrikson, M. (2002). Neurofunctional correlates of posttraumatic stress disorder: a PET symptom provocation study. Eur. Arch. Psychiatry Clin. Neurosci. 252, 68-75. doi: 10.1007/s004060200014

Rétey, J. V., Adam, M., Honegger, E., Khatami, R., Luhmann, U. F. O., Jung, H. H., et al. (2005). A functional genetic variation of adenosine deaminase affects the duration and intensity of deep sleep in humans. Proc. Natl. Acad. Sci. U.S.A. 102, 15676-15681. doi: 10.1073/pnas.0505414102

Roszell, D. K., McFall, M. E., and Malas, K. L. (1991). Frequency of symptoms and concurrent psychiatric disorder in Vietnam veterans with chronic PTSD. Hosp. Community Psychiatry 42, 293-296. doi: 10.1176/ps.42.3.293

Shapiro, F. (2001). Eye Movement Desensitization and Reprocessing (EMDR): Basic Principles, Protocols, and Procedures, 2nd Edn. New York, NY: Guilford Press. 
Shin, L. M., Rauch, S. L., and Pitman, R. K. (2006). Amygdala, medial prefrontal cortex, and hippocampal function in PTSD. Ann. N. Y. Acad. Sci. 1071, 67-79. doi: 10.1196/annals.1364.007

Stickgold, R. (2002). EMDR: a putative neurobiological mechanism of action. J. Clin. Psychol. 58, 61-75. doi: 10.1002/jclp.1129

Stickgold, R. (2008). Sleep-dependent memory processing and EMDR action. J. EMDR Pract. Res. 2, 289-299. doi: 10.1891/1933-3196.2.4.289

Trentini, C., Pagani, M., Fania, P., Speranza, A. M., Nicolais, G., Sibilia, A., et al. (2015). Neural processing of emotions in traumatized children treated with eye movement desensitization and reprocessing therapy: a hdEEG study. Front. Psychol. 6:1662. doi: 10.3389/fpsyg.2015.01662

Van Den Berg, D., de Bont, P. A., van der Vleugel, B. M., de Roos, C., de Jongh, A., Van Minnen, A., et al. (2015). Prolonged exposure versus eye movement desensitization and reprocessing versus waiting list for posttraumatic stress disorder in patients with a psychotic disorder. JAMA Psychiatry 72, 259-267. doi: 10.1001 /jamapsychiatry.2014.2637

van den Hout, M. A., Bartelski, N., and Engelhard, I. M. (2013). On EMDR: eye movements during retrieval reduce subjective vividness and objective memory accessibility during future recall. Cogn. Emot. 27, 177-183. doi: 10.1080/02699931.2012.691087

van den Hout, M. A., Engelhard, I. M., Rijkeboer, M. M., Koekebakker, J., Hornsveld, H., Leer, A., et al. (2011). EMDR: eye movements superior to beeps in taxing working memory and reducing vividness of recollections. Behav. Res. Ther. 49, 92-98. doi: 10.1016/j.brat.2010.11.003

van den Hout, M. A., Engelhard, I. M., Smeets, M. A. M., Hornsveld, H., Hoogeveen, E., de Heer, E., et al. (2010). Counting during recall: taxing of working memory and reduced vividness and emotionality of negative memories. Appl. Cogn. Psychol. 24, 303-311. doi: 10.1002/acp. 1677

van den Hout, M. A., Rijkeboer, M. M., Engelhard, I. M., Klugkist, I., Hornsveld, H., Toffolo, M. J. B., et al. (2012). Tones inferior to eye movements in the EMDR treatment of PTSD. Behav. Res. Ther. 50, 275-279. doi: 10.1016/j.brat.2012.02. 001

Wilson, D. L., Silver, S. M., Covi, W. G., and Foster, S. (1996). Eye movement desensitization and reprocessing: effectiveness and autonomic correlates. J. Behav. Ther. Exp. Psychiatry 27, 219-229. doi: 10.1016/S0005-7916(96) 00026-2

Zhu, Y., Du, R., Zhu, Y., Shen, Y., Zhang, K., Chen, Y., et al. (2016). PET mapping of neurofunctional changes in a posttraumatic stress disorder model. J. Nucl. Med. 57, 1474-1477. doi: 10.2967/jnumed.116. 173443

Conflict of Interest Statement: All authors have been invited as speakers in national and international EMDR conferences.

Copyright (C) 2017 Pagani, Amann, Landin-Romero and Carletto. This is an openaccess article distributed under the terms of the Creative Commons Attribution License (CC BY). The use, distribution or reproduction in other forums is permitted, provided the original author(s) or licensor are credited and that the original publication in this journal is cited, in accordance with accepted academic practice. No use, distribution or reproduction is permitted which does not comply with these terms. 